\title{
Land-Use Variations in Regions with Rapid Economic Development - A Case Study in the Pearl River Delta
}

\author{
M. M. Hu and B. C. Xia* \\ School of Environmental Science and Engineering, Sun Yat-sen University, Guangzhou 510275, China
}

Received 29 February 2020; revised 09 March 2020; accepted 12 March 2020; published online 31 March 2020

\begin{abstract}
This study evaluates land use/cover changes (LUCC), urban expansion, and landscape patterns in the Pearl River Delta (PRD) from 1995 to 2015. Specifically, by analyzing the spatial-temporal process and transfer direction of LUCC, as well as landscape pattern change, human activity and sustainable urban development can be better understood. The results show that forestland has the largest area (occupying more than 50\%) in all landscape types. The forest coverage rate of the PRD is relatively high; meanwhile, forestland presents a spatially distributed form of aggregation. Urban-land expansion is primarily driven by population growth and economic development. The LUCC is imbalanced and shows a one-way transition; the proportion of built-up land increased from $7.91 \%$ in 1995 to $14.34 \%$ in 2015 (urban expansion has nearly doubled in size). Foshan, Guangzhou, Shenzhen, and Dongguan have seen the most significant expansion of built-up land, primarily through the occupation of large amounts of forest and cropland. The landscape tends to be more fragmented and diversified. Human activities, as the main driving force, need to avoid the acceleration of the urbanization process to occupy a large amount of ecological land in future development.
\end{abstract}

Keywords: land use/cover change, landscape pattern, landscape heterogeneity, Pearl River Delta

\section{Introduction}

Land use has generally been considered a local environmental issue; however, it is becoming a force of global importance (Foley et al., 2005; Cai et al., 2007). Land use/cover change (LUCC) has essential impacts on regional ecological security and natural succession of ecosystems (Salazar et al., 2015; Yu et al., 2018; Hu et al., 2019). Therefore, studying of LUCC is desired for sustainable social-ecological systems.

Previously, there were several types of research on LUCC, which could be classified into four categories: exploring (1) the spatial-temporal analysis of LUCC (Jiao et al., 2019); (2) the effects of LUCC (economic impacts, environmental effects, ecological effects, etc.) (Du and Huang, 2017; Gong et al., 2020); (3) the driving mechanism of LUCC (Hasselmann et al., 2010; Li et al., 2020); and (4) the scenario prediction of LUCC (Dang and Kaisaki, 2017; Gomes et al., 2019). However, the amount of research on the spatial-temporal analysis of LUCC is the most due to it directly reflects the effects of climate change and human activities on the natural environment. Dewan and Yamaguchi (2009) evaluated LUCC and urban expansion in Greater Dhaka using satellite images and socio-economic data, which found that the land-use maps will contribute to both the development of sustainable urban land-use planning

*Corresponding author. Tel.: 86-20-31145320.

E-mail address: xiabch@mail.sysu.edu.cn (B. C. Xia).

ISSN: 2663-6859 print/2663-6867 online

(C) 2020 ISEIS All rights reserved. doi:10.3808/jeil.202000024. decisions and also for forecasting possible future changes. Velázquez et al. (2003) found that Oaxaca has lost over half a million hectares of forested areas during $1980 \sim 2001$; the core results may contribute to the understanding of how LUCC and GIS methods can provide more targeted information that may help to improve conservation policies and land use planning strategies.

Tremendous efforts have been made in studying the spatial-temporal analysis of LUCC. However, there is a limited report in analyzing changes in landscape patterns brought by LUCC and their interrelationships. Moreover, from a China perspective, there has been a crucial demand for scientific bases to dealing with economic development and land-use protection. This is especially true for Pearl River Delta (PRD) as located in the south of the country and with the highest GDP as well as rapid urban expansion.

Therefore, as an extension of the previous efforts, the objective of this study is to explore the LUCC and landscape change in the PRD using the multivariate methods and variables. Specifically, the purpose entails analyzing the spatial-temporal pattern on LUCC, the landscape distribution on a class level, the landscape heterogeneity, and LUCC impact on landscape pattern. Moreover, this study could provide a targeted suggestion that may help to improve environmental conservation policies and land use planning strategies.

\section{Overview of the Study Area}

The study area is the whole PRD region, which is an ag- 
glomeration located in Guangdong, southern China (Figure 1), and covers approximately $54,000 \mathrm{~km}^{2}$ with a subtropical climate. The PRD is one of the most densely urbanized regions in the world and consists of nine municipals, which are Guangzhou (GZ), Shenzhen (SZ), Foshan (FS), Dongguan (DG), Huizhou (HZ), Zhongshan (ZS), Zhuhai (ZH), Jiangmen (JM) and Zhaoqing (ZQ). The report released by the World Bank Group (2015) showed that the Pearl River Delta had become the most significant urban agglomeration in the world with the largest surface area and population. The PRD became a research hot spot due to the dramatic growth of economy, the rapid expansion of cities, and the location neighbored with Hong Kong and Macao (Hu and Xia, 2019). And it is being planned to be a world-class Grand Bay Area by China's government.

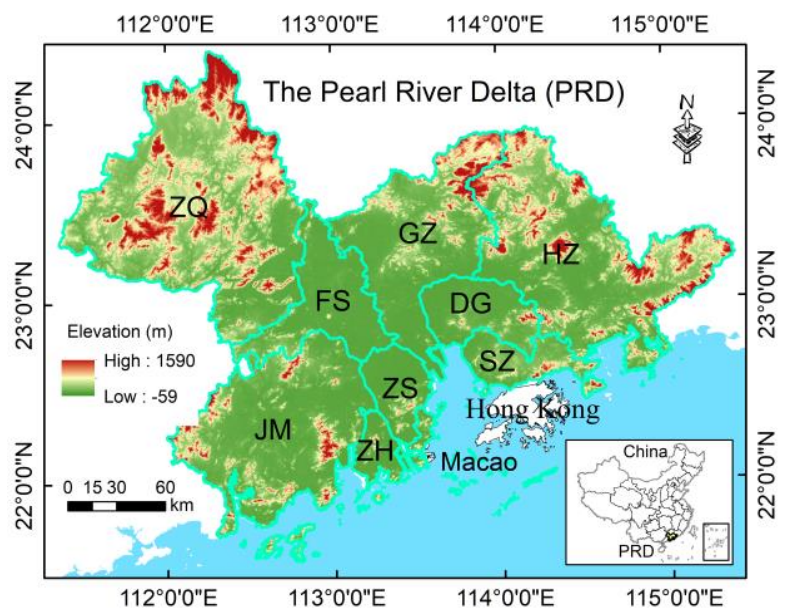

Figure 1. Location of the PRD.

\section{Methods}

\subsection{Data Resource}

Five land use/cover maps of PRD in 1995, 2000, 2005, 2010 and 2015 were downloaded from the Resources and Environmental Sciences, Chinese Academy of Sciences (RESDC) (http://www.resdc.cn). The Advanced Spaceborne Thermal Emission and Reflection Radiometer (ASTER) global digital elevation model (GDEM) with a resolution of $30 \mathrm{~m}$, which was used to obtain elevation (http://www.gscloud.cn/). The GDP and population data were collected from the Guangdong Statistical Yearbook (from 1996 to 2016).

\subsection{Land-Use Transition Matrix}

Firstly, this study attempted to employ a quantitative approach in exploring the spatial and temporal distribution of land use in the PRD. Moreover, ArcGIS 10.2 is used to measure the land-use transfer matrix (the application of Markov model to LUCC). The Markov model can not only quantitatively indicate the conversion between different land-use types, but also reveal the transfer rate between LUCC. Therefore, the characteristics of the transfer structure and direction of the regional LUCC can state entirely. The land-use transition matrix can be calculated as (Muller and Middleton, 1994):

$M_{L C} \cdot M_{t}=M_{t+1}$

The Markov chain equation is constricted using the landuse distributions at the beginning $\left(M_{t}\right)$ and at the end $\left(M_{t+1}\right)$ of a discrete time period as well as a transition matrix $\left(M_{L C}\right)$ representing the land-use changes that occurred during that period. It reflects the actual transition process of a system from time $t$ to time $t+1$, revealing the specific process of LUCC.

\subsection{Class Distribution Statistics}

A primary goal of landscape ecology is to understand the development of spatial heterogeneity. Landscape pattern index is a quantitative indicator that can highly condense the information of land use. Choosing a suitable index is very important for the rationality of landscape pattern analysis. Based on the research objectives and the ecological implications of each indicator, this study screened eight landscape indexes at the level of class metrics (Table 1). Class metrics are computed for every patch type/class in the landscape. Using ArcGIS 10.2 software, the land use data of the PRD from 1995 to 2015 are converted into raster data in BIL format. The pixel size (resolution) is set to $500 \mathrm{~m} \times 500 \mathrm{~m}$. Furthermore, the landscape pattern analysis of various selected indexes is performed based on the Fragstats 4.2 software. For details, refer to the tutorial of FRAGSTATS software(http://www.umass.edu/landeco/research/fragstats/documents/fragstats.help.4.2.pdf)

\subsection{Detection of Landscape Heterogeneity}

Landscape heterogeneity controls the regional consequences of processes occurring in ecosystems. Furthermore, it reflects the heterogeneity and complexity of land use and plays an essential role in controlling the ecological process of the landscape. In this study, landscape shape index (LSI), interspersion juxtaposition index (IJI), Shannon's diversity index (SHDI), and aggregation index (AI) are selected to analyze the landscape pattern of the PRD.

\section{Results and Discussion}

\subsection{Trends of LUCC}

Land use is mainly occupied by forestland, cropland and built-up land in the PRD. The main types of land use are different in different cities; the forestland is located primarily on Zhaoqing, Huizhou and Guangzhou. Built-up land is mainly located in Guangzhou, Foshan and Shenzhen. From 1995 to 2015, the land use structure in the PRD changed significantly (Figure 2). The main characteristics are the continuous growth of built-up land and the occupation of cropland and forestland. In detail, the expansion of built-up land spread from the Pearl River to the surroundings. Foshan, Guangzhou, Shenzhen and Dongguan have the most significant areas of urban-land expansion (Table 3). For example, the percentage of built-up land in Dongguan has increased from $28.6 \%$ in 2000 to $41.4 \%$ in 2005 ; it has a high-speed urban expansion. 
Table 1. Class Distribution Statistics

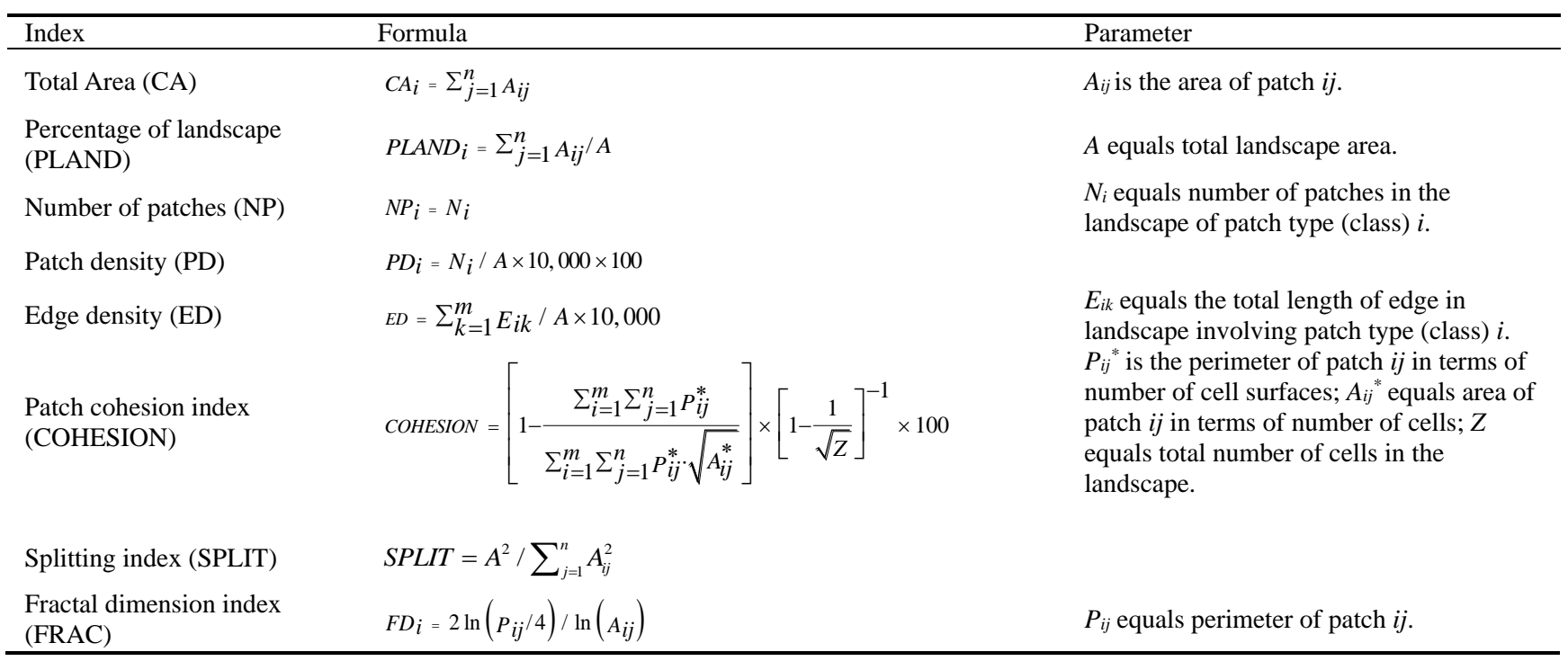

Table 2. Landscape Distribution Statistics

\begin{tabular}{|c|c|c|}
\hline Index & Formula & Parameter \\
\hline $\begin{array}{l}\text { Landscape shape } \\
\text { index (LSI) }\end{array}$ & $L S I=0.25 E^{*} / \sqrt{A}$ & $E^{*}$ equals total length of edge in landscape. \\
\hline $\begin{array}{l}\text { Interspersion } \\
\text { juxtaposition } \\
\text { index (IJI) }\end{array}$ & $I J I=-\sum_{i=1}^{m} \sum_{k=i+1}^{m}\left[\left(\frac{e_{i k}}{E}\right) \cdot \ln \left(\frac{e_{i k}}{E}\right)\right] \times 100 / \ln (0.5[m(m-1)])$ & $\begin{array}{l}E_{i k} \text { equals the total length of edge in landscape } \\
\text { between patch types } i \text { and } k ; E \text { equals total length of } \\
\text { edge in landscape, excluding background; } m \text { equals } \\
\text { number of patch types present in the landscape. }\end{array}$ \\
\hline $\begin{array}{l}\text { Shannon's } \\
\text { diversity index } \\
\text { (SHDI) }\end{array}$ & $S H D I=-\sum_{i=1}^{m}\left(P_{i} \times \ln P_{i}\right)$ & $\begin{array}{l}P_{i} \text { equals proportion of the landscape occupied by } \\
\text { patch type } i \text {. }\end{array}$ \\
\hline $\begin{array}{l}\text { Aggregation index } \\
\text { (AI) }\end{array}$ & $A I=\left[\sum_{i=1}^{m}\left(\frac{g_{i i}}{\max \rightarrow g_{i i}}\right) P_{i}\right](100)$ & $\begin{array}{l}g_{i i} \text { equals number of like adjacencies between pixels of } \\
\text { patch type } i \text { based on the single-count method; } \\
\text { max } \rightarrow g_{i i} \text { equals a maximum number of like } \\
\text { adjacencies between pixels of patch type } i \text { based on the } \\
\text { single-count method. }\end{array}$ \\
\hline
\end{tabular}

From 1995 to 2015 , the area of built-up land increased by $6.43 \%\left(3,466.09 \mathrm{~km}^{2}\right)$, the LUCC of the PRD mainly manifested in the conversion of other land types to built-up land (Table 4). The population (permanent population at the year-end) increased from 32.90 million in 1995 to 58.27 million in 2015. The increase in population is closely related to the increase in built-up land. Specifically, the area of cropland and forestland decreased by $4.34 \%\left(2,339.47 \mathrm{~km}^{2}\right)$ and $1.97 \%\left(1,061.93 \mathrm{~km}^{2}\right)$, respectively. It shows that the industrial transfer of the PRD has reduced the proportion of the primary industry. The percentage of the primary sector in GDP dropped from $5.4 \%$ to $1.8 \%$ during $1995 \sim 2015$. The interference of land use by human activities has increased, which is related to the transformation of industrial structure.

Furthermore, analyzing LUCC in different cities from 1995 to 2015 (Figure 3). The LUCC in all cities has shown the expansion of built-up land and the rapid decrease in cropland and forestland. Among them, the increase in built-up land in Shenzhen and Dongguan accounted for the highest proportion of the total administrative area. The percentage of built-up land in Shenzhen has doubled from $22.03 \%$ in 1995 to $44.06 \%$ in 2015. Similarly, the growing portion of built-up land in Dongguan accounts for $16.55 \%$. The area of built-up land in Foshan and Guangzhou increased the most considerable $\left(659.7 \mathrm{~km}^{2}\right.$ and $659.6 \mathrm{~km}^{2}$, respectively). The expansion of built-up land is obtained by occupying cropland and forest land.

For the land use structure in 2015, the proportion of forestland in Zhaoqing, Huizhou, and Guangzhou is more than $50 \%$; the forestland is the dominant landscape occupied in the PRD. The Zhaoqing's economic development is the lowest in the PRD; however, as approximately $70.1 \%$ forest coverage and contains a national nature reserve in there (Hu et al., 2019). Guangzhou presents the highest GDP and has a significantly high forest cover. It indicates that Guangzhou employed adequate environmental protection. There is also the similarity in Shenzhen; it has $46.44 \%$ forest coverage and the fastest economic growth rate in the PRD. Dongguan's water area accounts for $25.47 \%$ (with most complicated river network in the PRD), and forestland occupied $20.24 \%$, the land use mainly for builtup land $(35.35 \%)$. Consequently, the land use structure of 
Dongguan is relatively unreasonable. The government should pay more attention to ensuring that the ecological area is not over-occupied, while economic development is in progress.

Based on the transition matrix of land use types between 1995 and 2015, Figure 4 shows the land use transformation networks. Land use transfer in Shenzhen, Foshan, and Dongguan is more complicated, mainly other types of land transferred to construction land. Taking Shenzhen as an example, the cropland decreased by $10.65 \%$, the forestland decreased by $10.88 \%$, and the built-up land increased by $22.03 \%$. From the perspective of the reduction of forest land, Shenzhen has the most considerable decline, but forestland is still the primary land-use type in Shenzhen. The cropland in Dongguan decreased by
$10.49 \%$; the forestland decreased by $5.12 \%$, and the built-up land increased by $16.55 \%$. The urban-land expansion primarily driven by population growth and economic development. The direction and complexity of land-use change can be more clearly represented by using a transfer matrix diagram.

\subsection{Variance of Landscape Pattern}

The landscape index of patch size, scale, structure and combination in the PRD is calculated though Fragstats software (Figure 5). From 1990 to 2015, the area of built-up land continued to increase, and human activities continued to increase. The area of water area changed relatively gently, but show a

Table 3. The Change Trend of Land Use/Cover in the PRD from 1995 to 2015 (\%)

\begin{tabular}{|c|c|c|c|c|c|c|c|c|c|c|c|}
\hline & 1995 & 2000 & 2005 & 2010 & 2015 & & 1995 & 2000 & 2005 & 2010 & 2015 \\
\hline \multicolumn{7}{|c|}{ Guangzhou (GZ) } & \multicolumn{5}{|c|}{ Shenzhen (SZ) } \\
\hline Cropland & 38.8 & 37.5 & 35.5 & 32.9 & 32.1 & Cropland & 18.6 & 17.1 & 11.6 & 9.5 & 6.7 \\
\hline Forestland & 44.0 & 44.1 & 43.2 & 42.4 & 42.2 & Forestland & 53.2 & 48.2 & 46.6 & 42.4 & 41.5 \\
\hline Grassland & 1.4 & 1.4 & 1.5 & 1.3 & 1.3 & Grassland & 1.6 & 1.6 & 1.3 & 1.1 & 1.0 \\
\hline Water & 4.4 & 4.4 & 4.3 & 4.6 & 4.4 & Water & 2.2 & 2.2 & 2.3 & 2.1 & 2.2 \\
\hline Built-up land & 11.3 & 12.5 & 15.5 & 18.9 & 20.0 & Built-up land & 24.4 & 30.9 & 38.2 & 44.9 & 48.6 \\
\hline Unused land & 0.1 & 0.1 & 0.0 & 0.0 & 0.0 & Unused land & 0.0 & 0.0 & 0.0 & 0.0 & 0.0 \\
\hline \multicolumn{6}{|c|}{ Foshan (FS) } & & \multicolumn{5}{|c|}{ Dongguan (DG) } \\
\hline Cropland & 54.7 & 52.2 & 47.3 & 42.6 & 40.2 & Cropland & 31.7 & 31.2 & 22.9 & 18.3 & 16.4 \\
\hline Forestland & 23.7 & 23.5 & 22.9 & 22.4 & 22.1 & Forestland & 30.2 & 29.5 & 25.4 & 24.9 & 23.3 \\
\hline Grassland & 0.5 & 0.5 & 0.5 & 0.2 & 0.2 & Grassland & 3.7 & 3.5 & 3.1 & 2.7 & 2.5 \\
\hline Water & 6.1 & 6.0 & 5.9 & 6.1 & 6.0 & Water & 7.3 & 7.2 & 7.2 & 8.6 & 7.1 \\
\hline Built-up land & 15.0 & 17.8 & 23.3 & 28.7 & 31.5 & Built-up land & 27.2 & 28.6 & 41.4 & 45.5 & 50.7 \\
\hline Unused land & 0.0 & 0.0 & 0.0 & 0.0 & 0.0 & Unused land & 0.0 & 0.0 & 0.0 & 0.0 & 0.0 \\
\hline \multicolumn{7}{|c|}{ Huizhou (HZ) } & \multicolumn{5}{|c|}{ Zhongshan (ZS) } \\
\hline Cropland & 24.4 & 22.9 & 25.2 & 24.5 & 22.9 & Cropland & 58.3 & 57.4 & 48.9 & 44.7 & 42.0 \\
\hline Forestland & 65.8 & 67.0 & 65.3 & 64.9 & 64.6 & Forestland & 23.7 & 23.2 & 21.0 & 20.9 & 20.5 \\
\hline Grassland & 2.5 & 2.4 & 2.5 & 2.5 & 2.4 & Grassland & 0.2 & 0.2 & 0.2 & 0.2 & 0.2 \\
\hline Water & 2.1 & 2.2 & 2.2 & 1.6 & 2.2 & Water & 5.3 & 5.3 & 5.3 & 5.3 & 5.2 \\
\hline Built-up land & 5.2 & 5.5 & 4.9 & 6.5 & 7.9 & Built-up land & 12.4 & 14.0 & 24.6 & 29.0 & 32.1 \\
\hline Unused land & 0.0 & 0.0 & 0.0 & 0.0 & 0.0 & Unused land & 0.0 & 0.0 & 0.0 & 0.0 & 0.0 \\
\hline \multicolumn{6}{|c|}{ Zhuhai (ZH) } & & \multicolumn{5}{|c|}{ Jiangmen (JM) } \\
\hline Cropland & 46.0 & 44.9 & 42.5 & 40.7 & 38.3 & Cropland & 34.8 & 34.4 & 34.8 & 34.0 & 33.4 \\
\hline Forestland & 37.2 & 35.8 & 35.2 & 34.2 & 33.9 & Forestland & 52.0 & 52.2 & 52.0 & 51.2 & 50.9 \\
\hline Grassland & 0.6 & 0.5 & 0.4 & 0.5 & 0.5 & Grassland & 3.4 & 3.4 & 3.4 & 3.5 & 3.5 \\
\hline Water & 5.9 & 5.3 & 4.8 & 4.8 & 4.8 & Water & 4.0 & 3.9 & 4.0 & 4.0 & 3.9 \\
\hline Built-up land & 10.2 & 13.5 & 17.0 & 19.7 & 22.5 & Built-up land & 5.7 & 6.1 & 5.8 & 7.2 & 8.3 \\
\hline Unused land & 0.1 & 0.0 & 0.1 & 0.0 & 0.0 & Unused land & 0.0 & 0.0 & 0.0 & 0.0 & 0.0 \\
\hline \multicolumn{7}{|c|}{ Zhaoqing (ZQ) } & \multicolumn{5}{|c|}{ Pearl River Delta (PRD) } \\
\hline Cropland & 18.1 & 18.2 & 18.0 & 17.9 & 17.8 & Cropland & 30.2 & 29.4 & 28.4 & 26.9 & 25.9 \\
\hline Forestland & 76.3 & 75.9 & 75.9 & 75.5 & 75.3 & Forestland & 56.4 & 56.3 & 55.4 & 54.7 & 54.4 \\
\hline Grassland & 1.6 & 1.6 & 1.6 & 1.8 & 1.8 & Grassland & 2.0 & 2.0 & 2.0 & 2.0 & 2.0 \\
\hline Water & 2.1 & 2.1 & 2.2 & 2.2 & 2.2 & Water & 3.5 & 3.4 & 3.4 & 3.4 & 3.4 \\
\hline Built-up land & 1.9 & 2.1 & 2.3 & 2.6 & 2.9 & Built-up land & 7.9 & 8.9 & 10.8 & 12.9 & 14.4 \\
\hline Unused land & 0.0 & 0.0 & 0.0 & 0.0 & 0.0 & Unused land & 0.0 & 0.0 & 0.0 & 0.0 & 0.0 \\
\hline
\end{tabular}

Table 4. Land Use Transfer Matrix (\%)

\begin{tabular}{|c|c|c|c|c|c|c|c|c|}
\hline & \multicolumn{7}{|c|}{1995} \\
\hline & & Cropland & Forestland & Grassland & Water & Built-up land & Unused land & Total \\
\hline \multirow{7}{*}{2015} & Cropland & 24.74 & 0.35 & 0.09 & 0.13 & 0.63 & 0 & 25.95 \\
\hline & Forestland & 0.34 & 53.70 & 0.13 & 0.02 & 0.14 & 0 & 54.34 \\
\hline & Grassland & 0.01 & 0.30 & 1.64 & 0.01 & 0.01 & 0 & 1.96 \\
\hline & Water & 0.11 & 0.05 & 0.02 & 3.20 & 0.02 & 0 & 3.40 \\
\hline & Built-up land & 5.08 & 1.91 & 0.15 & 0.09 & 7.10 & 0.01 & 14.34 \\
\hline & Unused land & 0 & 0 & 0 & 0 & 0 & 0 & 0 \\
\hline & Total & 30.29 & 56.31 & 2.03 & 3.45 & 7.91 & 0.02 & 100.00 \\
\hline
\end{tabular}



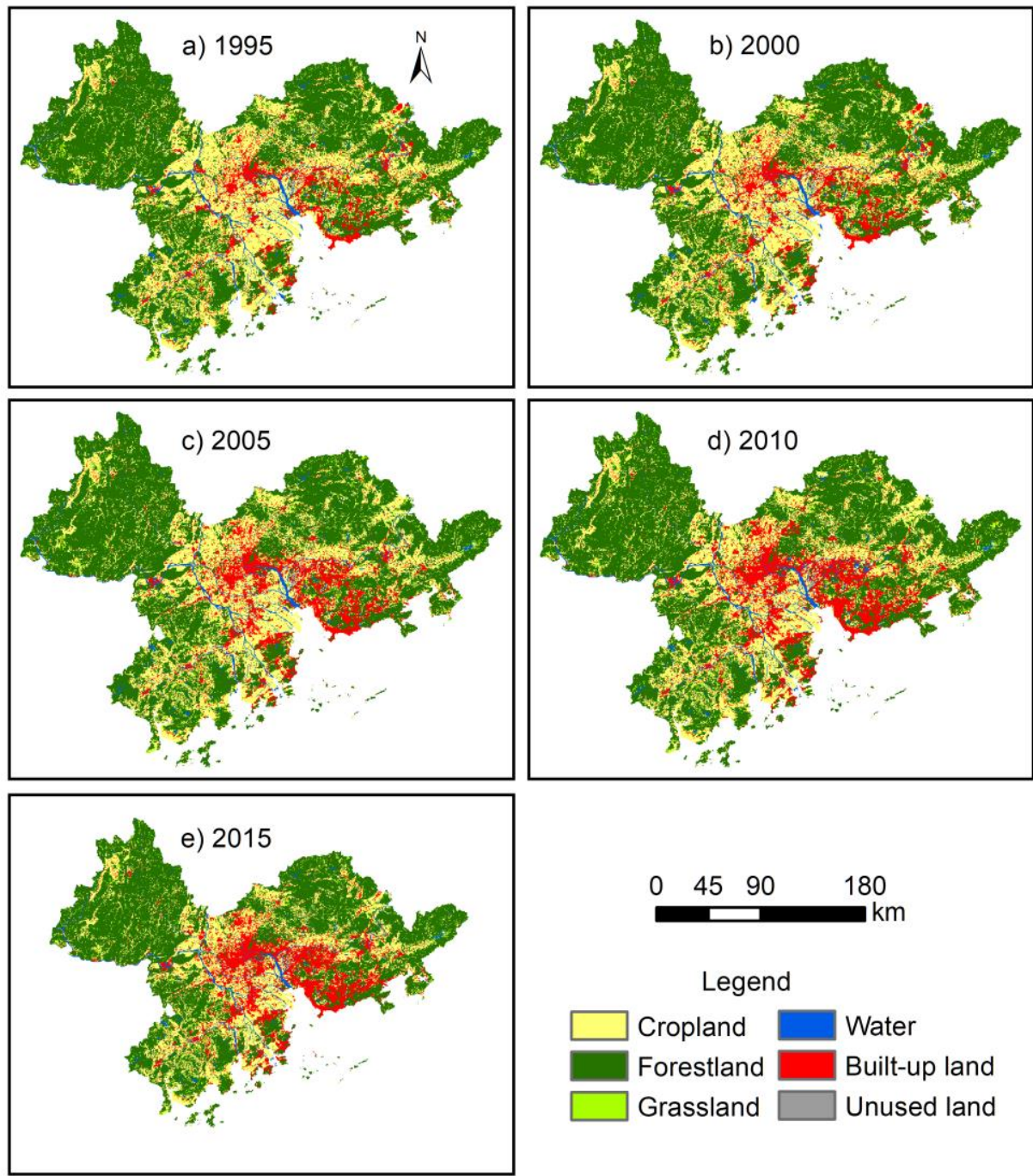

Figure 2. The LUCC in the PRD from 1995 to 2015.
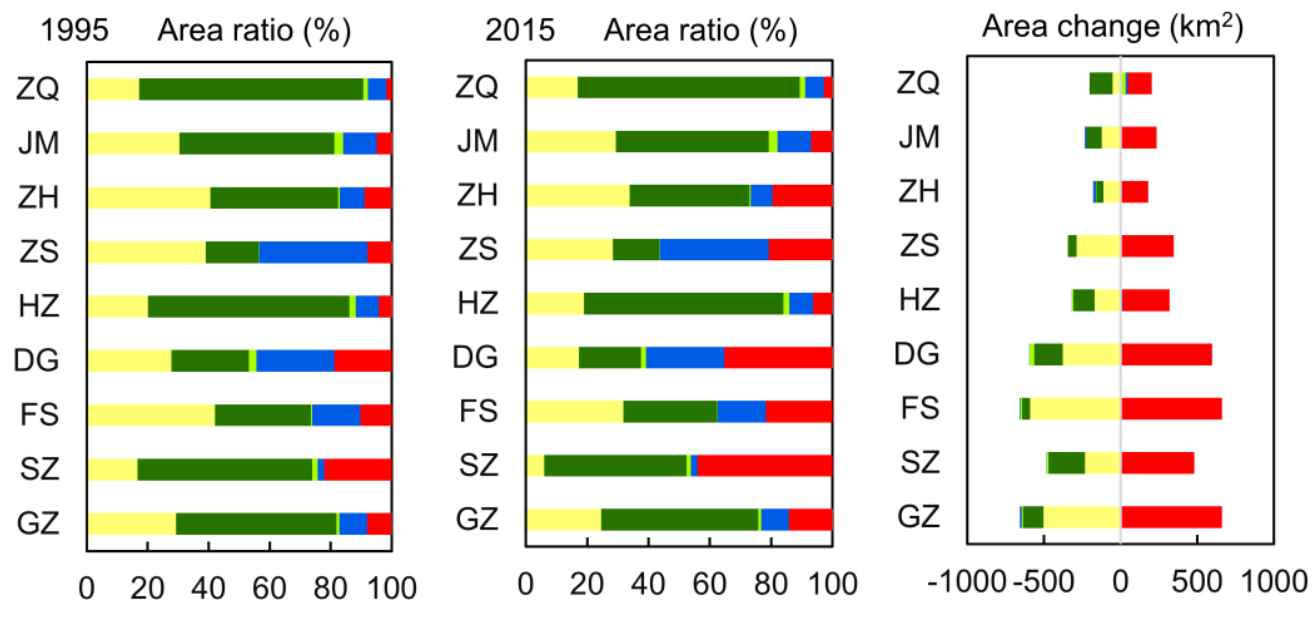

Cropland

- Forestland

घrassland $\quad$ Water $\quad$ Built-up land $\quad$ Unused land

Figure 3. LUCC in different cities. 

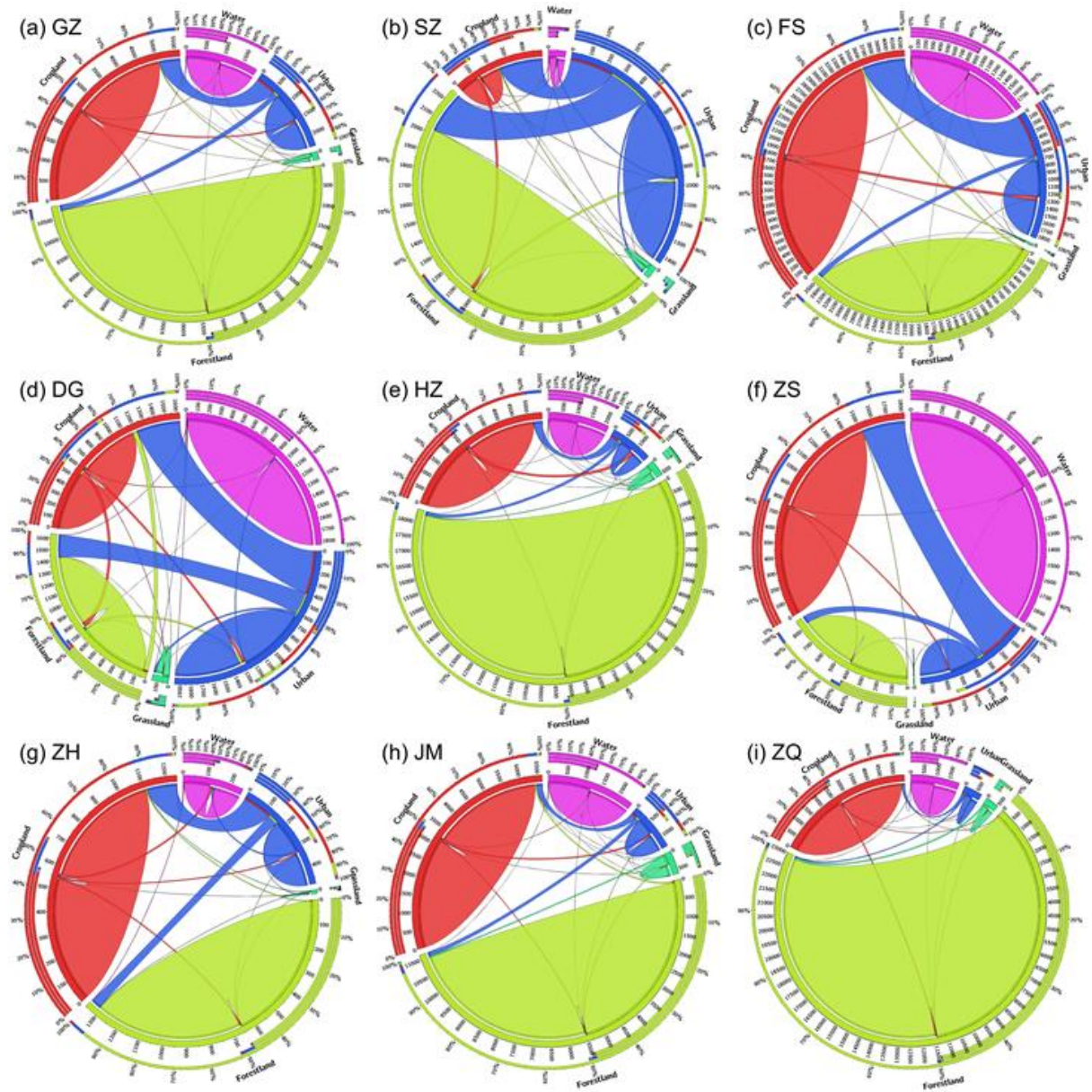

Figure 4. Land-use type transformation network in different cities.

downward trend, from $1859.7 \mathrm{~km}^{2}$ in 1995 to $1832.8 \mathrm{~km}^{2}$ in 2015. The area of cropland shows a significant downward trend; it means that the industrial structure has changed, and the proportion of primary industry has decreased significantly. The land use pattern is forestland $>$ cropland $>$ built-up land $>$ water area $>$ grassland $>$ unused land.

Affected by human activities, the edge density (ED) of cropland is the largest in all landscapes, showing a declining trend. There is a significant increase in ED of built-up land; the landscape heterogeneity is correspondingly improved. The dynamic characteristics of forestland are similar to the built-up land. From 1995 to 2000, the number of patches (NP) of builtup land is the largest, and it of cropland ranks second. However, from 2000 to 2015, the NP of cropland is the largest, and it of built-up land ranks second. It showed that the fragmentation of cropland increased and the scale of farming decreased. Builtup land presents the opposite trend, and the phenomenon of clustering is more noticeable. Mainly due to the acceleration of the urbanization process, the region witnesses a vigorous expansion of built-up land. Moreover, large areas of forestland are more conducive to the protection of biodiversity and the environment.

The value of fractal dimension is cropland > forestland > grassland $>$ built-up land $>$ water area $>$ unused land $>1$. The fractal dimension index of cropland and forestland is the largest with the most complicated shape. However, the fractal dimension of the forestland has decreased, which indicates that human disturbance is increasing. In contrast, the fractal dimension index of built-up land is closer to 1 . It means that the builtup land with strong self-similarity, regular and simple shape. Furthermore, the cohesion index of built-up land has increased from 89.27 in 1995 to 98.07 in 2015 . It shows that the built-up land presents agglomerated expansion mode, alleviates the negative effects of habitat fragmentation, and has a corresponding promotion effect on regional diversity protection. The cohesion index of unused land is fluctuating, showing a downward trend; It indicates that the transformation of unused land by human beings has increased, and unused land tends to be scattered.

There is a notable difference in patch density (PD) of different landscapes, among which the increase in grassland patch density is the most obvious. The PD of built-up land shows a downward trend. Urban expansion on the basis of original spatial distribution, which leads to the decreasing number of patches and the clustering pattern of land use. The split index of cropland has increased from 0.978 in 1995 to 0.997 in 2015. With 

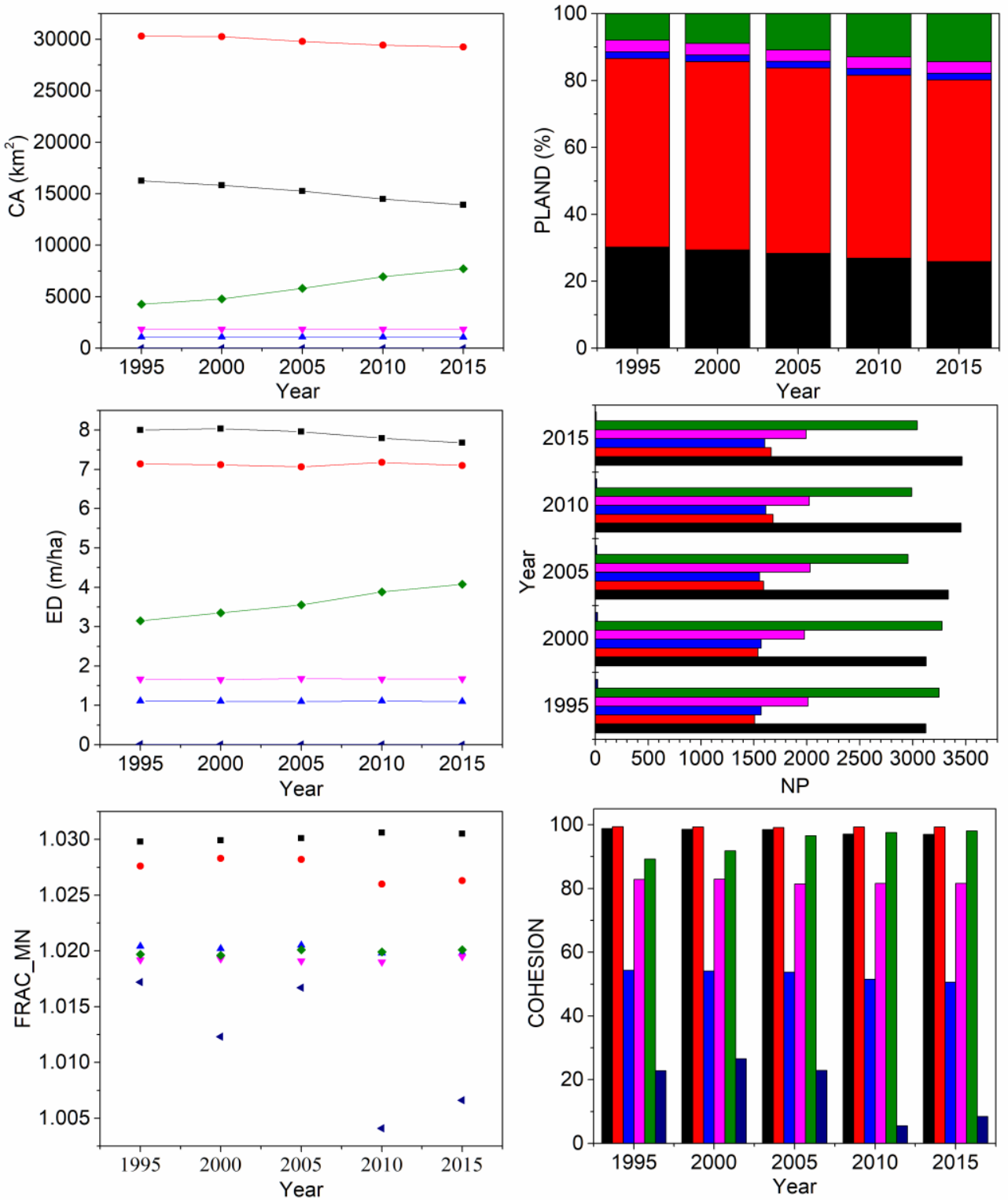

- Cropland - Forestland \ Grassland

- Water • Built-up land ^ Unused land

$$
\text { Cropland Forestland Grassland }
$$
Water $\square$ Built-up land $\square$ Unused land

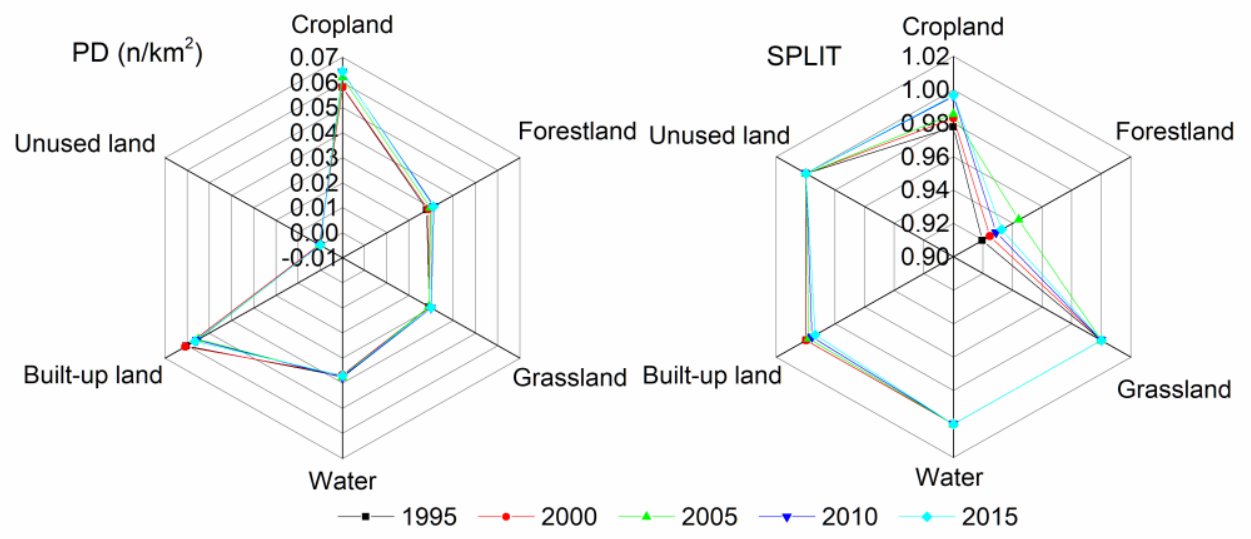

Figure 5. Patch characteristics of land use in the PRD from 1990 to 2015. 
(a) LSI

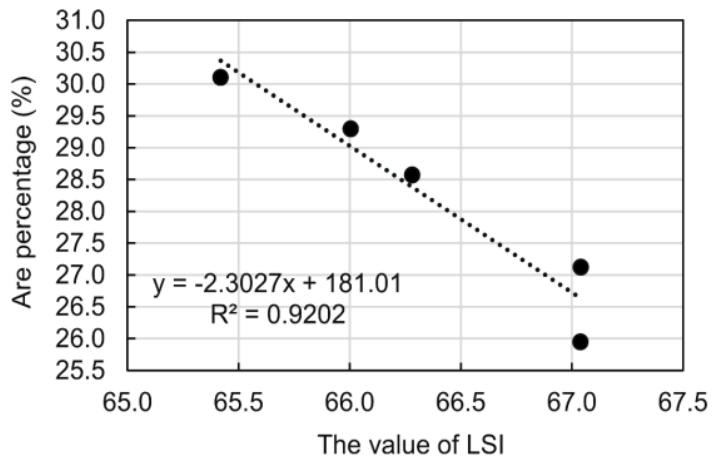

(c) Al

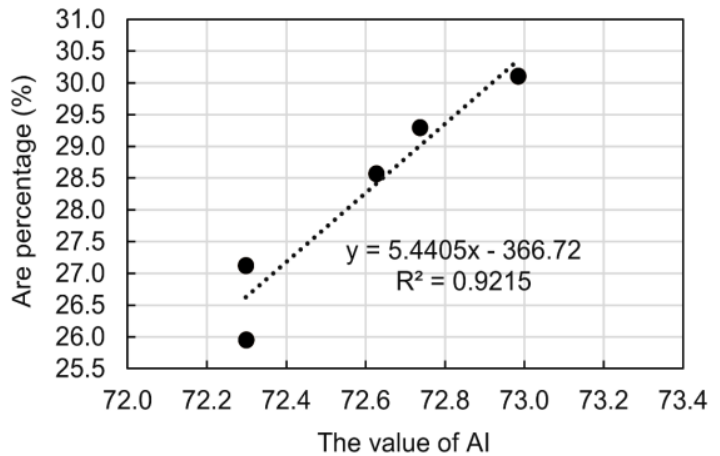

(b) IJ

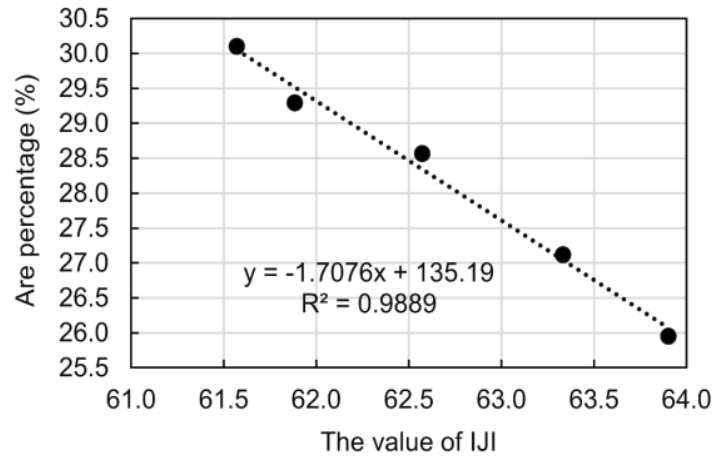

(d) SHDI

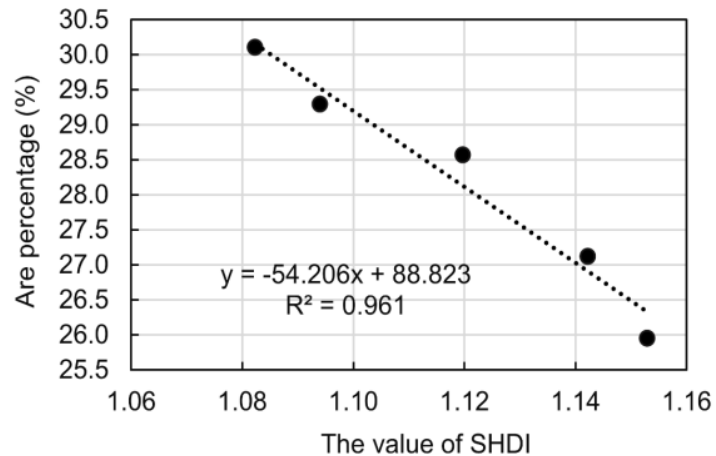

Figure 6. Relationship between cropland and landscape metrics: (a) LSI; (b) IJI; (c) AI; and (d) SHDI.

(a) LSI

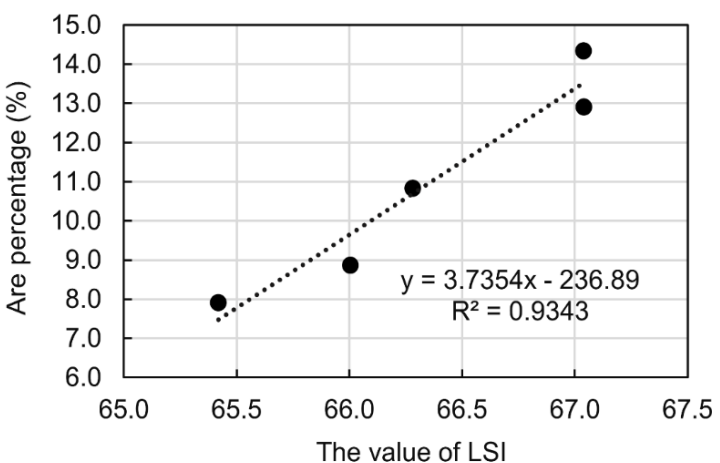

(c) $\mathrm{Al}$

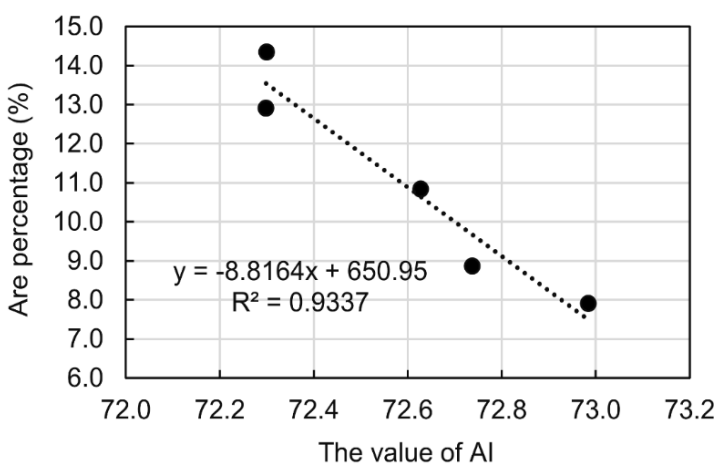

(b) IJI

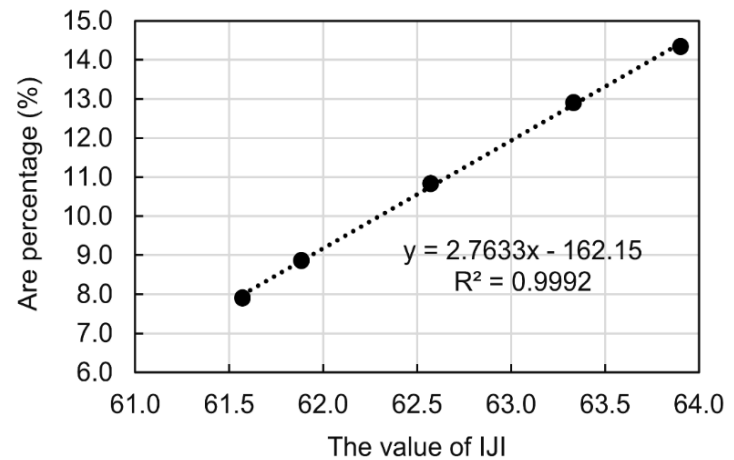

(d) SHDI

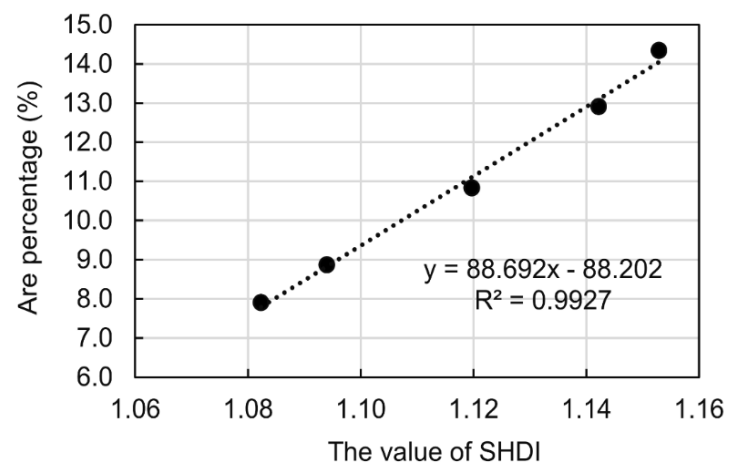

Figure 7. Relationship between built-up land and landscape metrics: (a) LSI, (b) IJI, (c) AI, and (d) SHDI. 
the development of urbanization, a large amount of the cropland has requested by urban industrialization, and the extensive management of farmland in rural areas has become a serious phenomenon. The small-scale of self-cultivated land and decentralized collective agricultural has become an obstacle to the development of agricultural modernization (Ye, 2015). Meanwhile, the split index of forestland has increased due to the influence of human activities.

From 1995 to 2015, the LSI increases by 1.618, indicating that the landscape shape of the PRD has become more irregular, and the perimeter has gradually increased (Table 5). The increase in IJI means that one patch type is adjacent to more other classes, and the complexity of the landscape has grown. The most popular diversity index is Shannon's diversity index (SHDI). For details, SHDI is risen from 1.082 in 1995 to 1.153 in 2015, indicating an increase in landscape diversity. A decrease in AI means a reduction in the degree of patch type aggregation. Overall, the landscape shape tends to become more complex and the pattern of different patch types appearing alternately more apparent. The landscape index indicates that the interference from human activities is increasing in the PRD.

Table 5. Landscape Metrics for the PRD from 1995 to 2015

\begin{tabular}{ccccc}
\hline & LSI & IJI & SHDI & AI \\
\hline 1995 & 65.419 & 61.570 & 1.082 & 72.984 \\
2000 & 66.004 & 61.883 & 1.094 & 72.737 \\
2005 & 66.280 & 62.572 & 1.120 & 72.627 \\
2010 & 67.040 & 63.332 & 1.142 & 72.298 \\
2015 & 67.037 & 63.901 & 1.153 & 72.300 \\
\hline
\end{tabular}

\subsection{LUCC impact on landscape pattern}

The results show that LUCC has changed significantly, with imbalanced and a one-way transition. Landscapes tend to be more fragmented and diversified. The relationship between LUCC and landscape pattern shows that changes in cropland and built-up land may be the main driving factors of observed landscape pattern changes. LUCC is caused by both natural and human activities (Liu et al., 2017; Guo et al., 2019), with the latter being the major driving forces in the rapid urbanization process (Huang et al., 2014).

With the economic development and population growth, the area of the built-up area has nearly doubled, and with the imbalance of the one-way transition (the change of cropland and forestland to construction land), some positive changes in landscape phenomena have occurred. LUCC has a direct impact on landscape patterns. Analyzing the interaction between land use and landscape patterns can help improve the effectiveness of land use management (Nagendra et al., 2004; Abdullah and Nakagoshi, 2006). From the PRD, different types of patches tend to be more complicated, the diversity is increased, and the agglomeration is reduced. It is the concrete manifestation of landscape heterogeneity and the result of various ecological processes.
Figure 6 shows the relationship between the area percentage of cropland and landscape indexes, indicating that changes in cropland directly affect the landscape pattern. The area percentage of cropland showing a downward trend, from $30.29 \%$ in 1995 to $25.95 \%$ in 2015 . The landscape tends to be more complex, the higher diversity and lower aggregation. The impact of built-up land on the landscape pattern of the study area is significant, and the correlation coefficient is higher (Figure 7). When the area percentage of built-up land is increased, the LSI, IJI and SHDI will increase, and AI will decrease.

\section{Conclusion}

This study reveals the spatial-temporal changes in landuse coverage and landscape pattern changes in the PRD from 1995 to 2015. Twelve landscape indexes are selected from the perspectives of class and landscape distribution statistics. Finally, we comprehensively analyze the impact of LUCC on landscape pattern.

Overall, the area percentage of built-up land increase from $7.91 \%$ in 1995 to $14.34 \%$ in 2015 , and the urban expansion nearly doubled. The prominent built-up land expansions find in Foshan, Guangzhou, Shenzhen and Dongguan; mainly though the occupation of large amounts of forest and cropland. Forestland has the largest area in all landscape types, occupying more than $50 \%$, and has the largest cohesion index. It shows that the forest coverage rate of the PRD is relatively high, and with the form of spatial cluster distribution. Urban expansion on the basis of original spatial distribution, which leads to the decreasing number of patches and the clustering pattern of land use. More patches in cropland mean weak connectivity; thus, the landscape is more fragmented. With the development of urbanization, a large amount of the cropland has occupied by urban industrialization, and the extensive management of farmland in rural areas has become a serious phenomenon. Human activities, as the main driving force, need to avoid the acceleration of urbanization process to occupy a large amount of ecological land in future development. This study could provide more targeted information that may support to improve environment-friendly policies and land use planning strategies.

Acknowledgments. This research was supported by the International Program for Ph.D. Candidates Sun Yat-Sen University.

\section{References}

Abdullah, S.A., and Nakagoshi, N. (2006). Changes in landscape spatial pattern in the highly developing state of Selangor, peninsular Malaysia. Landscape and Urban Planning, 77(3), 263-275. https: //doi.org/10.1016/j.landurbplan.2005.03.003

Cai, Y., Huang, G., Nie, X., Li, Y., and Tan, Q. (2007). Municipal solid waste management under uncertainty: a mixed interval parameter fuzzy-stochastic robust programming approach. Environmental Engineering Science, 24(3), 338-352. https://doi.org/10.1089/ees. 2005.0140

Dang, A.N., and Kaisaki, A. (2017). Integrating biophysical and socioeconomic factors for land-use and land-cover change projection in agricultural economic regions. Ecological Modelling, 344, 29-37. 
https://doi.org/10.1016/j.ecolmodel.2016.11.004

Dewan, A.M., and Yamaguchi, Y. (2009). Land use and land cover change in Greater Dhaka, Bangladesh: Using remote sensing to promote sustainable urbanization. Applied Geography, 29(3), 390401. https://doi.org/10.1016/j.apgeog.2008.12.005

Du, X., and Huang, Z. (2017). Ecological and environmental effects of land use change in rapid urbanization: The case of hangzhou, China. Ecological Indicators, 81, 243-251. https://doi.org/10.1016/j.eco lind.2017.05.040

Foley, J.A., DeFries, R., Asner, G.P., Barford, C., Bonan, G., Carpenter, S.R., Chapin, F.S., Coe, M.T., Daily, G.C., Gibbs, H.K., Helkowski, J.H., Holloway, T., Howard, E.A., Kucharik, C.J., Mofreda, C., Patz, J.A., Prentice, C., Ramankutty, N., and Snyder, P.K. (2005). Global Consequences of Land Use. Science, 309(5734), 570-574. https: //doi.org/10.1126/science.1111772

Gomes, E., Abrantes, P., Banos, A., and Rocha, J. (2019). Modelling future land use scenarios based on farmers' intentions and a cellular automata approach. Land Use Policy, 85, 142-154. https://doi.org/ 10.1016/j.landusepol.2019.03.027

Gong, Z., Gu, L., Yao, S., and Deng, Y. (2020). Effects of bio-physical, economic and ecological policy on forest transition for sustainability of resource and socioeconomics development. Journal of Cleaner Production, 243, 118571. https://doi.org/10.1016/j.jclepro. 2019.118571

Guo, G., Wu, Z., and Chen, Y. (2019). Complex mechanisms linking land surface temperature to greenspace spatial patterns: Evidence from four southeastern Chinese cities. Science of the Total Environment, 674, 77-87. https://doi.org/10.1016/j.scitotenv.20 19.03.402

Hasselmann, F., Csaplovics, E., Falconer, I., Bürgi, M., and Hersperger, A.M. (2010). Technological driving forces of LUCC: Conceptualization, quantification, and the example of urban power distribution networks. Land Use Policy, 27(2), 628-637. https://doi.org/10.1016/ j.landusepol.2009.08.016

Hu, M., Li, Z., Yuan, M., Fan, C., and Xia, B. (2019). Spatial differentiation of ecological security and differentiated management of ecological conservation in the Pearl River Delta, China. Ecological Indicators, 104, 439-448. https://doi.org/10.1016/j.ecolind. 2019.04.081

Hu, M., and Xia, B. (2019). A significant increase in the normalized difference vegetation index during the rapid economic development in the Pearl River Delta of China. Land Degradation and Development, 30(4), 359-370. https://doi.org/10.1002/ldr.3221

Huang, C., Wang, X., Yang, H., Li, Y., Wang, Y., Chen, X., and Xu, L. (2014). Satellite data regarding the eutrophication response to human activities in the plateau lake Dianchi in China from 1974 to 2009. Science of the Total Environment, 485-486, 1-11. https: //doi.org/10.1016/j.scitotenv.2014.03.031

Huang, G. H., Baetz, B. W., Patry, G. G., and Terluk, V. (1997). Capacity planning for an integrated waste management system under uncertainty: a North American case study. Waste Management \& Research, 15(5), 523-546. https://doi.org/10.1177/0734242X97015 00507

Huang, G. H., Cohen, S. J., Yin, Y. Y., and Bass, B. (1996). Incorporation of inexact dynamic optimization with fuzzy relation analysis for integrated climate change impact study. Journal of Environmental Management, 48(1), 45-68. https://doi.org/10.1006/jema. 1996.0065

Jiao, M., Hu, M., and Xia, B. (2019). Spatiotemporal dynamic simulation of land-use and landscape-pattern in the Pearl River Delta, China. Sustainable Cities and Society, 49, 101581. https: //doi.org/10.1016/j.scs.2019.101581

Li, B., Shi, X., Lian, L., Chen, Y., Chen, Z., and Sun, X. (2020).
Quantifying the effects of climate variability, direct and indirect land use change, and human activities on runoff. Journal of Hydrology, 584, 124684. https://doi.org/10.1016/j.jhydrol.2020.124 684

Li, Y. F., Li, Y. P., Huang, G. H., and Chen, X. (2010). Energy and environmental systems planning under uncertainty-an inexact fuzzy-stochastic programming approach. Applied Energy, 87(10), 3189-3211. https://doi.org/10.1016/j.apenergy.2010.02.030

Liu, X., Liang, X., Li, X., Xu, X., Ou, J., Chen, Y., Li, S., Wang, S. and Pei, F. (2017). A future land use simulation model (FLUS) for simulating multiple land use scenarios by coupling human and natural effects. Landscape and Urban Planning, 168, 94-116. https://doi.org/10.1016/j.landurbplan.2017.09.019

Maqsood, I., Huang, G., Huang, Y., and Chen, B. (2005). ITOM: an interval-parameter two-stage optimization model for stochastic planning of water resources systems. Stochastic Environmental Research and Risk Assessment, 19(2), 125-133. https://doi.org/ 10.1007/s00477-004-0220-6

Muller, M.R., Middleton, J.A. (1994). Markov model of land-use change dynamics in the Niagara Region, Ontario, Canada. Landscape Ecology, 9, 151-157. https://doi.org/10.1007/BF0012438

Nagendra, H., Munroe, D.K., and Southworth, J. (2004). From pattern to process: landscape fragmentation and the analysis of land use/land cover change. Agriculture, Ecosystems and Environment, 101(2), 111-115. https://doi.org/10.1016/j.agee.2003.09.003

Salazar, A., Baldi, G., Hirota, M., Syktus, J., and McAlpine, C. (2015). Land use and land cover change impacts on the regional climate of non-Amazonian South America: A review. Global and Planetary Change, 128, 103-119. https://doi.org/10.1016/j.gloplacha.2015. 02.009

Tan, Q., Huang, G. H., and Cai, Y. P. (2011). Radial interval chanceconstrained programming for agricultural non-point source water pollution control under uncertainty. Agricultural Water Management, 98(10), 1595-1606. https://doi.org/10.1016/j.agwat.2011.05. 013

Velázquez, A., Durán, E., Ramírez, I., Mas, J.F., Bocco, G., Ramírez, G., and Palacio, J.L. (2003). Land use-cover change processes in highly biodiverse areas: the case of Oaxaca, Mexico. Global Environmental Change, 13(3), 175-184. https://doi.org/10.1016/S 0959-3780(03)00035-9

Weng, S. Q., Huang, G. H., and Li, Y. P. (2010). An integrated scenario-based multi-criteria decision support system for water resources management and planning-A case study in the Haihe River Basin. Expert Systems with Applications, 37(12), 8242-8254. https://doi. org/10.1016/j.eswa.2010.05.061

Wu, S., Huang, G., and Guo, H. (1997). An interactive inexact-fuzzy approach for multiobjective planning of water resource systems. Water Science and Technology, 36(5), 235-242. https://doi.org/ 10.1016/S0273-1223(97)00479-4

Ye, J. (2015). Land Transfer and the Pursuit of Agricultural Modernization in China. Journal of Agrarian Change, 15(3), 314-337. https: //doi.org/10.1111/joac.12117

Yu, H., Huang, G. H., An, C. J., and Wei, J. (2011). Combined effects of DOM extracted from site soil/compost and biosurfactant on the sorption and desorption of PAHs in a soil-water system. Journal of Hazardous Materials, 190(1-3), 883-890. https://doi.org/10.1016/ j.jhazmat.2011.04.026

Yu, G., Li, M., Tu, Z., Yu, Q., Jie, Y., Xu, L., Dang Y, and Chen, X. (2018). Conjugated evolution of regional social-ecological system driven by land use and land cover change. Ecological Indicators, 89, 213-226. https://doi.org/10.1016/j.ecolind.2018.01.065 